\title{
Tex 19 Paralogs Exhibit a Gonad and Placenta-Specific Expression in the Mouse
}

\author{
Catherine CELEBI ${ }^{1,2}$, Aafke VAN MONTFOORT ${ }^{3)}$, Valérie SKORY1), Emmanuelle KIEFFER ${ }^{1}$, \\ Sandra KUNTZ4), Manuel MARK ${ }^{1,2)}$ and Stéphane VIVILLE ${ }^{1,2)}$ \\ 1) Institut de Génétique et de Biologie Moléculaire et Cellulaire (IGBMC), Institut National de Santé et de Recherche \\ Médicale (INSERM) U964/Centre National de Recherche Scientifique (CNRS) UMR 1704/Université de Strasbourg, \\ 67404 Illkirch, France \\ ${ }^{2)}$ Service de Biologie de la Reproduction, Centre Hospitalier Universitaire, Strasbourg F-67000, France \\ 3) IVF Laboratory, Dept. of Obstetrics and Gynaecology, GROW-School for Oncology and Developmental Biology, \\ Maastricht University Medical Center, PO Box 5800, Maastricht, the Netherlands \\ 4) Laboratoire de Biologie Expérimentale, EA 3442 "Aspects cellulaires et moléculaires de la reproduction et du \\ développement," Faculté des Sciences, BP239, Vandoeuvre les Nancy cedex, France
}

\begin{abstract}
We have previously suggested that TEX19, a mammalian-specific protein of which two paralogs exist in rodents, could be implicated in stem cell self-renewal and pluripotency. We have established here the expression profiles of Tex19.1 and Tex19.2 during mouse development and adulthood. We show that both genes are coexpressed in the ectoderm and then in primordial germ cells (PGCs). They are also coexpressed in the testis from embryonic day 13.5 to adulthood, whereas only Tex19.1 transcripts are detected in the developing and adult ovary as well as in the placenta and its precursor tissue, the ectoplacental cone. The presence of both Tex19.1 and Tex19.2 in PGCs, gonocytes and spermatocytes opens the possibility that these two genes could play redundant functions in male germ cells. Furthermore, the placental expression of Tex19.1 can explain why Tex19.1 knockout mice show embryonic lethality, in addition to testis defects.
\end{abstract}

Key words: Embryo, Gonad development, In situ hybridization, Placenta, Spermatogenesis

(J. Reprod. Dev. 58: 360-365, 2012)

$\mathbf{T}$ ex19 (Testis expressed gene 19) was initially identified as testis specific through a cDNA subtraction strategy [1]. Tex19 is restricted to mammals, is present as a unique gene in humans, and has been duplicated in the mouse and rat giving rise to the paralogs Tex19.1 and Tex19.2. Through protein comparison in 11 mammalian species, two highly Tex19-conserved domains named MCP and VPTEL domains have been characterized [2]. However, none of them shares homologies with known proteins, therefore preventing any functional prediction. Interestingly, an N-Ter cysteine was recently found to be bound to Ubr2, which may help Tex19 stabilization [3].

Analysis of Tex19.1 knockout (KO) mice highlights a critical role for Tex19 in spermatogenesis, where it seems to act as a repressor of transposable elements. It was also reported that about half of the homozygous pups are missing, suggesting a function of Tex19.1 in survival during the perinatal period $[4,5]$. It was further shown that Tex19.1 is expressed by different pluripotent stem cells such as embryonic stem (ES), embryonic germ (EG) and embryonic carcinoma cells (ECC) and that the pattern of Tex19.1 expression almost parallels that of Oct4, a canonical marker of cell pluripotency. Altogether, these latter observations suggest that Tex19.1,

Received: April 13, 2011

Accepted: February 15, 2012

Published online in J-STAGE: March 9, 2012

(C)2012 by the Society for Reproduction and Development

*Correspondence: S Viville (e-mail: viville@igbmc.fr) as well as its human ortholog, could be a new factor involved in the maintenance of self-renewal or pluripotency of stem cells. Up to now, the expression patterns of Tex19.1 and Tex19.2 have been essentially analyzed by RT-PCR [2], thus limiting the amount of information on the cell types expressing these genes.

With the aim of helping to evaluate Tex19.1 and Tex19.2 functions, we decided to precisely determine their expression patterns at the cellular level by in situ hybridization (ISH) of whole mounts and/or histological sections from E (embryonic day) 7.5 to adulthood. Our results indicate notably that Tex19.1 and Tex19.2 expression patterns mostly overlap in male mice and thus that functional redundancy between these two genes could attenuate the Tex19.1 KO phenotype.

\section{Materials and Methods}

\section{Embryos and gonads}

CD1 mice were housed in an animal facility licensed by the French Ministry of Agriculture (agreement No. B67-218-5) and animal experiments were supervised by MM (agreements No. 67-62) who is qualified in mouse experimentations, in compliance with the European legislation on care and use of laboratory animals. The morning of finding a vaginal plug was designated day 0.5 of pregnancy. Adults were at least 8 weeks old.

In situ hybridization (ISH) on histological sections and whole mount in situ hybridization (WISH) analyses

ISH and WISH were performed with Oct4 (312 bp), Tex19.1 (487 
Table 1. Primer sequences and RT-PCR conditions for mouse Tex19.1, Tex19.2, Oct4 and $\beta$-actin genes

\begin{tabular}{|c|c|c|c|c|c|}
\hline Gene & Primer name & Primers sequence & $\begin{array}{c}\text { Annealing } \\
\text { temperature } \\
(\text { Ann T) }\end{array}$ & $\begin{array}{l}\text { Fragment } \\
\text { size }\end{array}$ & PCR program \\
\hline \multirow{2}{*}{ Mouse $\beta$-actin } & AHX 298 (sense) & CAGAGCAAGAGAGGTATCCT & \multirow{2}{*}{$58 \mathrm{C}$} & \multirow{2}{*}{$507 \mathrm{bp}$} & \multirow{2}{*}{$\begin{array}{l}96 \mathrm{C}: 5 \mathrm{~min} \\
94 \mathrm{C}: 30 \mathrm{sec} \\
58 \mathrm{C}: 30 \mathrm{sec} \\
72 \mathrm{C}: 10 \mathrm{sec} \\
72 \mathrm{C}: 10 \mathrm{~min}\end{array}$} \\
\hline & AHX 299 (antisense) & CATCTCCTGCTCGAAGTCTA & & & \\
\hline \multirow{2}{*}{ Mouse Tex 19.1} & AHW 110 (sense) & TTGTGGTACTGACTACCACC & \multirow{2}{*}{$58 \mathrm{C}$} & \multirow{2}{*}{$487 \mathrm{bp}$} & \multirow{8}{*}{$\begin{array}{l}\text { 95 C: } 15 \mathrm{~min} \\
94 \mathrm{C}: 30 \mathrm{sec} \\
\text { Ann. T C: } 1 \mathrm{~min} 30 \mathrm{sec} \\
72 \mathrm{C}: 1 \mathrm{~min} 30 \mathrm{sec} \\
72 \mathrm{C}: 10 \mathrm{~min}\end{array}$} \\
\hline & AHW 111 (antisense) & AAGGAGCACGAGTAACGAAC & & & \\
\hline \multirow{2}{*}{ Mouse Tex 19.2} & AHW 112 (sense) & AGGGACTGGTGCTTGTACCA & \multirow{2}{*}{$58 \mathrm{C}$} & \multirow{2}{*}{$414 \mathrm{bp}$} & \\
\hline & AHW 113 (antisense) & ACAGGGCACGAACTGAGCAA & & & \\
\hline \multirow{2}{*}{ Mouse Oct4 } & AER 61 (sense) & CACGAGTGGAAAGCAACTCA & \multirow{2}{*}{$58 \mathrm{C}$} & \multirow{2}{*}{519 bp } & \\
\hline & EBR 136 (antisense) & CTCGAACCACATCCTTCTCT & & & \\
\hline \multirow{2}{*}{$\begin{array}{l}\text { Mouse Tex } 9.1 \text { and } \\
\text { Tex } 19.2 \text { (Duplex PCR) }\end{array}$} & AHB 124 (sense) & TTGGAGCAAGTGTGAAGCTG & \multirow{2}{*}{$60 \mathrm{C}$} & $\begin{array}{c}566 \text { bp } \\
(\text { Tex 19.1) }\end{array}$ & \\
\hline & AHB 125 (antisense) & ATCCAGGGGTACAGCTTCCT & & $\begin{array}{c}496 \mathrm{bp} \\
(\text { Tex 19.2) }\end{array}$ & \\
\hline
\end{tabular}

bp) and Tex19.2 (414 bp) probes. The Oct4 probe, which strongly labels PGCs and germ cells (GCs) within gonads, is helpful to follow PGC migration and gonad location of GCs during embryogenesis and adulthood. WISH was performed on whole embryos at developmental stages when gonads could not be dissected and on gonads when the ISH signal of sections was too weak to be informative. RNA sense and antisense digoxigenin-labeled probes were synthesized using a Dig RNA Labeling Kit (Roche Diagnostics, Basel, Switzerland) according to manufacturer's instructions.

For WISH analyses, embryos or dissected gonads (with mesonephros attached) were collected and fixed in $4 \%(\mathrm{w} / \mathrm{v})$ paraformaldehyde (PFA) in phosphate-buffered saline (PBS), $\mathrm{pH} \mathrm{7.2,} \mathrm{at} 4 \mathrm{C}$, for $4 \mathrm{~h}$ (for embryos until E7.5 and gonads) or over night (for E8.5 and older embryos). After rinsing the samples twice in PBS containing $0.1 \%$ Tween (PBT), the samples were dehydrated in methanol diluted in PBT (from $25 \%$ to $100 \%$ ) and stored at $-20 \mathrm{C}$. After rehydration in PBT, the samples were treated as previously described [6] with a modified washing solution (2X SSC, $50 \%$ formamide and $1 \%$ SDS) and $0.05 \mathrm{~g} / \mathrm{ml}$ polyvinyl alcohol (Sigma P1763, Saint-Louis, MO, USA).

Sections destined for ISH were prepared as described [2]. In brief, ten-micrometer-thick sections of fresh-frozen tissues were postfixed for 10 min in PFA in PBS at $4 \mathrm{C}$ before the prehybridization step. Hybridization was performed over night at $70 \mathrm{C}$ with the appropriate denatured probes in a humid chamber. Then sections were washed, and the probe was revealed. Sections were counterstained either with $0.01 \%$ safranin or with 4'-,6-diamidino-2-phenylindole dihydrochloride (DAPI).

\section{RNA analyses}

Embryos and gonads dissected for RNA extraction were either dry frozen or kept in the appropriate amount of RLT buffer (Qiagen, Hilden, Germany) according to the manufacturer in liquid nitrogen before keeping them at $-80 \mathrm{C}$. Total RNA was prepared after thawing on ice using a Midi or Mini extraction kit (Qiagen), according to material quantity and the manufacturer's instructions. Reverse transcription of total RNA was performed using Superscript ${ }^{\circledR}$ II Reverse Transcriptase (Invitrogen, Carlsbad, CA, USA). Simplex PCR amplifications of Oct4, Tex19.1 and Tex19.2 genes from gonad and embryo cDNAs were performed using a PCR program with a master mix Kit (Qiagen). Duplex PCR amplification of Tex19.1 and Tex19.2 from extraembryonic tissue cDNAs was performed using a master mix kit (Qiagen). All $\beta$-actin and Oct4 PCR amplifications were performed with Roche Taq polymerase (Roche Diagnosis) and a master mix kit (Qiagen), respectively. All experiments were performed according to manufacturers' instructions. Conditions are described in Table 1. Oct4 was used as a positive control for the presence of germ cells, and $\beta$-actin was used as a positive control for RNA extraction.

\section{Results}

The expression pattern of Tex19.1 and Tex19.2 was analyzed by RT-PCR and/or ISH in whole mounts or histological sections of embryos and gonads using probes specific for each gene transcript. Oct4 was used both as a marker of primordial germ cells (PGC) [7] and of ES cell pluripotency [8].

\section{Expression of Tex19.1 in the placenta and sexually undifferentiated embryos}

Tex19.1 was strongly expressed in the ectoplacental cone at E7.5 as assessed by ISH (C, Fig. 1A and 3A) as well as in the placenta at E9.5 and E10.5 and, to a lesser extent, at E13.5 and E17.5, as assessed by RT-PCR analysis (Fig. 1C). At E13.5, expression of Tex19.1 in the placenta was restricted to spongiotrophoblast cells in the junctional zone (J, Fig. 1B) and to some cells in the trabeculae 


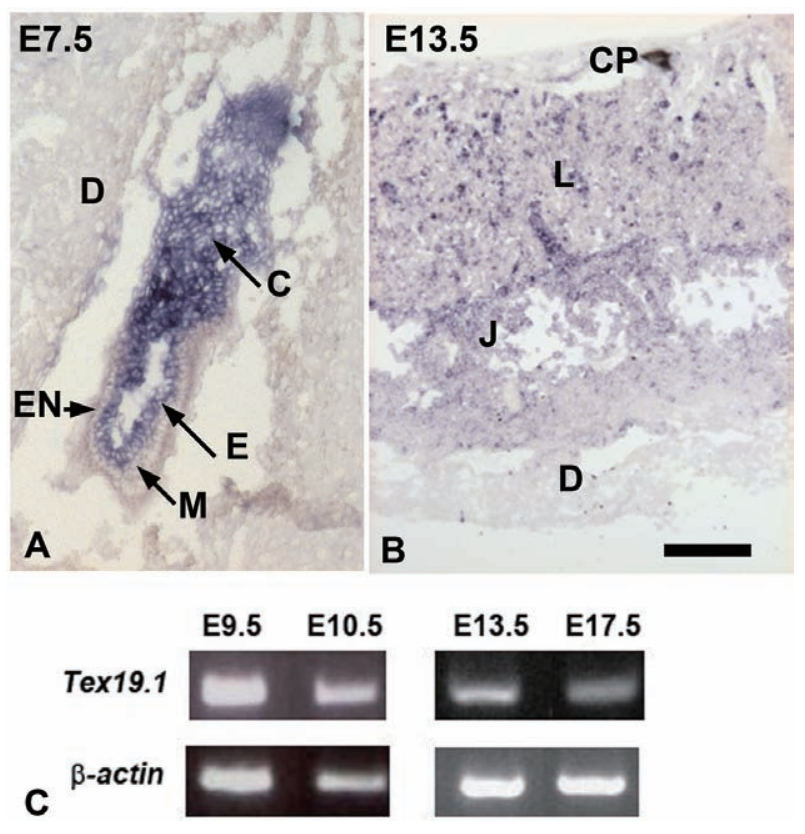

Fig. 1. Expression of Tex19.1 in the ectoplacental cone (E7.5) and placenta (E9.5 to E17.5). (A and B) ISH (purple signal) in histological sections at E7.5 and E13.5. C, ectoplacental cone; $\mathrm{CP}$, chorionic plate; D, maternal decidua; E, ectoderm; EN, endoderm; J, junctional zone of the placenta; $\mathrm{L}$, labyrinthine zone of the placenta; M, mesoderm. Bar in B: $80 \mu \mathrm{m}$ (A) and $300 \mu \mathrm{m}$ (B). (C) RT-PCR analyses of Tex19.1 and $\beta$-actin gene expression in the placenta at E9.5, E10.5, E13.5 and E17.5.

in the labyrinthine zone (L, Fig. 1B).

Embryonic expression of Tex 19.1, is present in the E3.5 blastocyst [2] and was found at E6.5 in the present study (Fig. 2). At E7.5, Tex19.1 transcripts were present in the ectoderm (E, Fig. 1A and 3A). At E8.5, Tex19.1 was detected in the embryo, exclusively in a region of the posterior hindgut known to contain Oct4-positive PGCs (arrows in Fig. 3D, E [9]), and accordingly, a faint signal was observed by RT-PCR at this age (Fig. 2). Tex19.1 was detected in the hindgut at E9.5 (arrow in Fig. 3F) and then in the nascent gonad at E11.5 (G, Fig. 3I). From E8.5 to E11.5, Tex19.1 expression almost paralleled that of Oct4, with the exception of the ectoplacental cone, where Oct4 transcripts were absent (Fig. 3). This observation strongly suggests that, similarly to Oct4, Tex19.1 is expressed in migrating primordial germ cells and then in gonocytes prior to the onset of sexual differentiation.

\section{Expression of Tex19.1 in the developing and adult testis}

Using ISH, Tex19.1 expression was detected in seminiferous cords of the embryonic and fetal testis at E12.5, E13.5 and E16.5 (SC, Fig. 4A, D and G). In histological sections, ISH signals revealed expression in gonocytes $(\mathrm{G})$ at E16.5 and E18.5 (Fig. 5A, B, G and $\mathrm{H}$ ), with the staining looking like that of Oct4, a germ cell-specific marker during development and after birth (Fig. 5E, F, K and L). At this stage, gonocytes are located in the center of seminiferous cords and have a clear nucleus. After birth, Tex19.1 expression was still restricted to gonocytes $(\mathrm{G})$ at $\mathrm{P} 1$ (Fig. $5 \mathrm{M}$ and $\mathrm{N}$ ) and at P5 (Fig. 5S

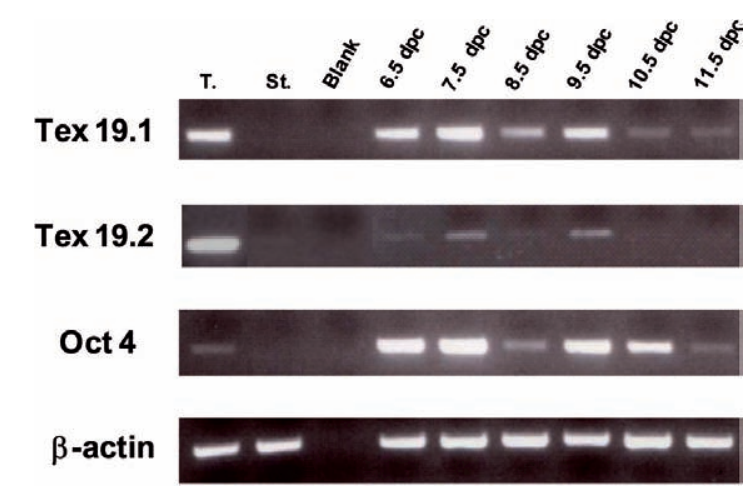

Fig. 2. RT-PCR analyses of Tex19.1, Tex19.2, Oct4 and $\beta$-actin gene expression in embryos. Blank: PCR run with water. Adult stomach $(\mathrm{St})$ and testis $(\mathrm{T})$ were used as negative and positive controls, respectively.

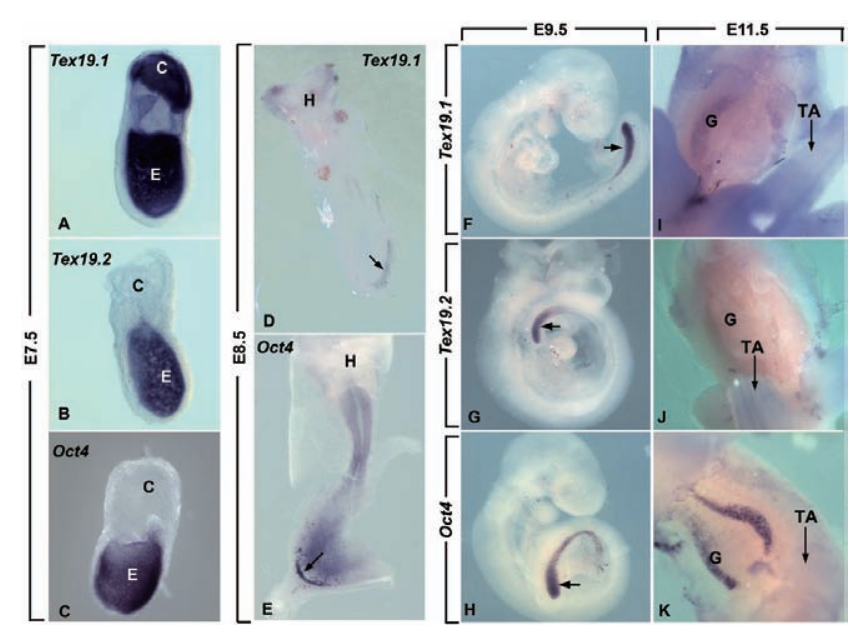

Fig. 3. ISH analysis of Tex19.1, Tex19.2 and Oct4 expression in sexually undifferentiated embryos. ISH signals are purple. C, ectoplacental cone; E, ectoderm; H, head folds; G, gonad; TA, tail. Arrows point to the hindgut. Embryos in A-C, D and E, $\mathrm{F}-\mathrm{H}$ and $\mathrm{I}-\mathrm{K}$ were photographed at the same magnifications, respectively.

and T). Tex19.1 staining follows cell margination, which is specific of germ cells at this stage of development. The same process is observed with Oct4 ISH, as shown in Fig. 5 (G, Fig. 5Q, R, W and $\mathrm{X})$. In the adult, Tex19.1 transcripts were present in pachytene (P) spermatocytes (Fig. 6A-D). In contrast, Oct4 expression in sexually mature testes was specifically detected in round spermatids $(\mathrm{R})$ at stages VII and VIII of the seminiferous epithelium cycle (Fig. 6I and $\mathrm{J}$ ), as previously described [10].

\section{Expression of Tex19.1 in the developing and adult ovary}

Tex19.1 expression was detected in the embryonic and fetal ovary at E12.5, E13.5 and E16.5 (O, Fig. 7A, D and G), and in the prepubertal ovary at P1 (OO, Fig. 7J). At all these developmental stages, the Tex19.1 expression profile was similar to that of Oct4 and was thus restricted to oocytes (OO, Fig. 7J). Likewise, in the 


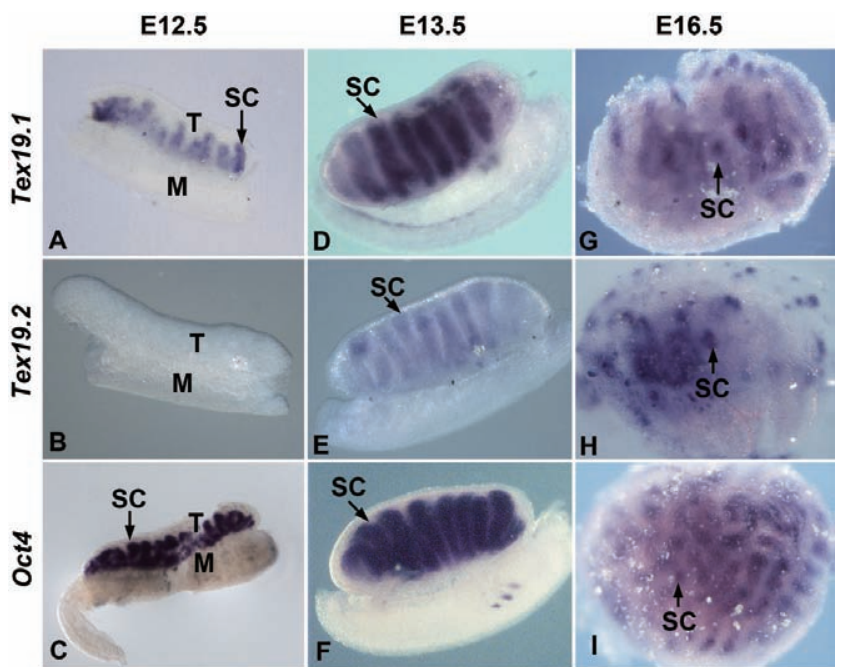

Fig. 4. ISH analysis of Tex19.1, Tex19.2 and Oct4 expression in the developing testis from E12.5 to E16.5. M, mesonephros; SC, seminiferous cords; T, testis. ISH signals are purple in wholemount ISH. Pictures A-C, D-F and G-I were photographed at the same magnifications, respectively.

adult ovary, expression of Tex19.1 and Oct4 corresponded to that of oocytes (OO, Fig. 7 M-P).

\section{Expression of Tex19.2}

Tex19.2 was undetectable in the placenta and in its precursor, the ectoplacental cone, at all studied developmental stages (C, Fig. 3B and data not shown). Tex19.2 transcripts were present in the ectoderm of E7.5 embryos and undetectable in E8.5 embryos by RT-PCR (Fig. 2) and ISH (data not shown). At E9.5, Tex19.2 was expressed in the hindgut of the embryos in a pattern similar to that of Tex19.1 and Oct4 (arrow, Fig. 3G, compared with F and H). No expression was observed at E11.5 (e.g., G in Fig. 3J) or in the testis at E12.5 (T, Fig. 4B). In the male gonad from E13.5 to E16.5, Tex19.2 expression was restricted to the seminiferous cords (SC, Fig. 4E and H). In histological sections, ISH revealed its expression in gonocytes at E16.5 (G, Fig. 5C and D), which were located in the center of seminiferous cords at this stage, with the same staining as Oct4, a germ cell-specific marker (G, Fig. 5E and F). At E18.5, Tex19.2 expression appeared almost restricted to Sertoli cells (S, Fig. 5I and J), as previously described [2], with weak expression remaining in gonocytes (G, Fig. 5I and J). At E16.5 and E18.5, Sertoli cells were located at the periphery of seminiferous cords and had a darker nucleus compared with gonocytes, which were centrally located and had a clearer nucleus. The gonocyte-specific staining was confirmed by the staining observed in Oct4 ISH sections (G, Fig. 5E, F, K and L). Soon after birth, at P1 and P5, Tex19.2 transcripts were detected mainly, if not exclusively, in Sertoli cells (S, Fig. $5 \mathrm{O}, \mathrm{P}, \mathrm{U}$ and $\mathrm{V}$ ), although some weak expression in gonocytes was not possible to rule out (G, Fig. 5O, P, U and V). At these stages, Sertoli cell cytoplasm occupies the majority of the central part of the tubules, and germ cells are marginating, with a clearer nucleus. Indeed, gonocyte-specific staining but not Sertoli cell staining is

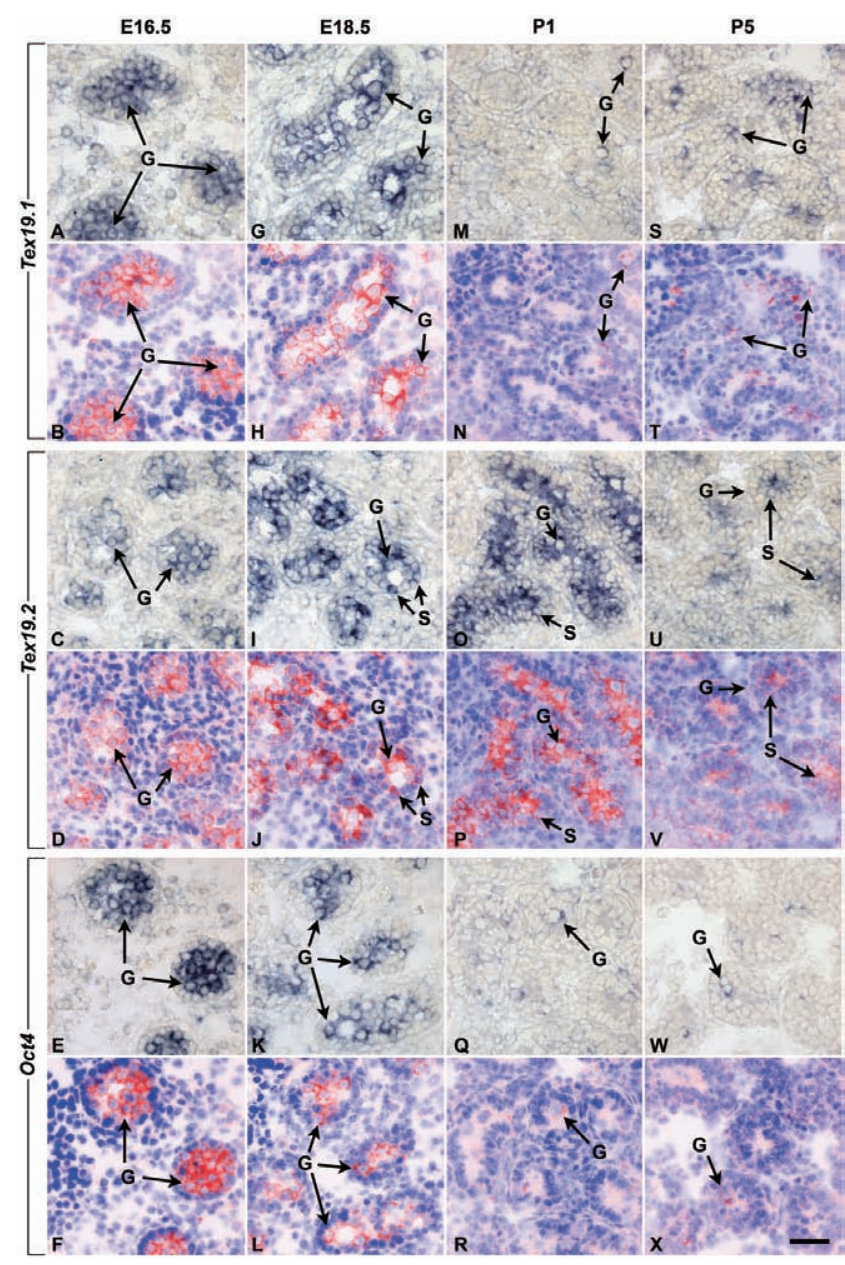

Fig. 5. ISH analysis of Tex19.1, Tex19.2 and Oct4 expression in the developing testis from E16.5 to P5. G, gonocyte; S, Sertoli cells. Histological sections were counterstained with 4'-6-diamidino2-phenylindole dihydrochloride (DAPI), and the ISH signals were converted into a red false color in the merged pictures (B, H, N, T, D, J, P, V, F, L, R and X, respectively). Note that Sertoli cell cytoplasm, which contains Tex 19.2 transcripts, occupies the center of the seminiferous cords at postnatal days 1 and 5 . Bar in X: $80 \mu \mathrm{m}(\mathrm{A}-\mathrm{X})$.

observed in Oct4 ISH sections (Fig. 5Q, R, W and X). In adult testes, Tex19.2 transcripts were restricted to pachytene spermatocytes, with some variation in the intensity of the ISH signal depending on the stage of the seminiferous epithelium cycle (P, Fig. 6E-H).

In the female gonad after E12.5, almost no expression was observed except at E13.5 and E16.5, at which time a very faint signal could be observed (Fig. 7B, E and H) that was similar to that of Oct4 at these stages (Fig. 7F, I). After birth, no signal could be seen in ISH sections (Fig. 7K) or in the adult ovary, as found by RT-PCR [2].

\section{Discussion}

The Tex19 gene was first identified as a unique gene and with a male germ cell-specific expression [11]. Subsequently, we showed 


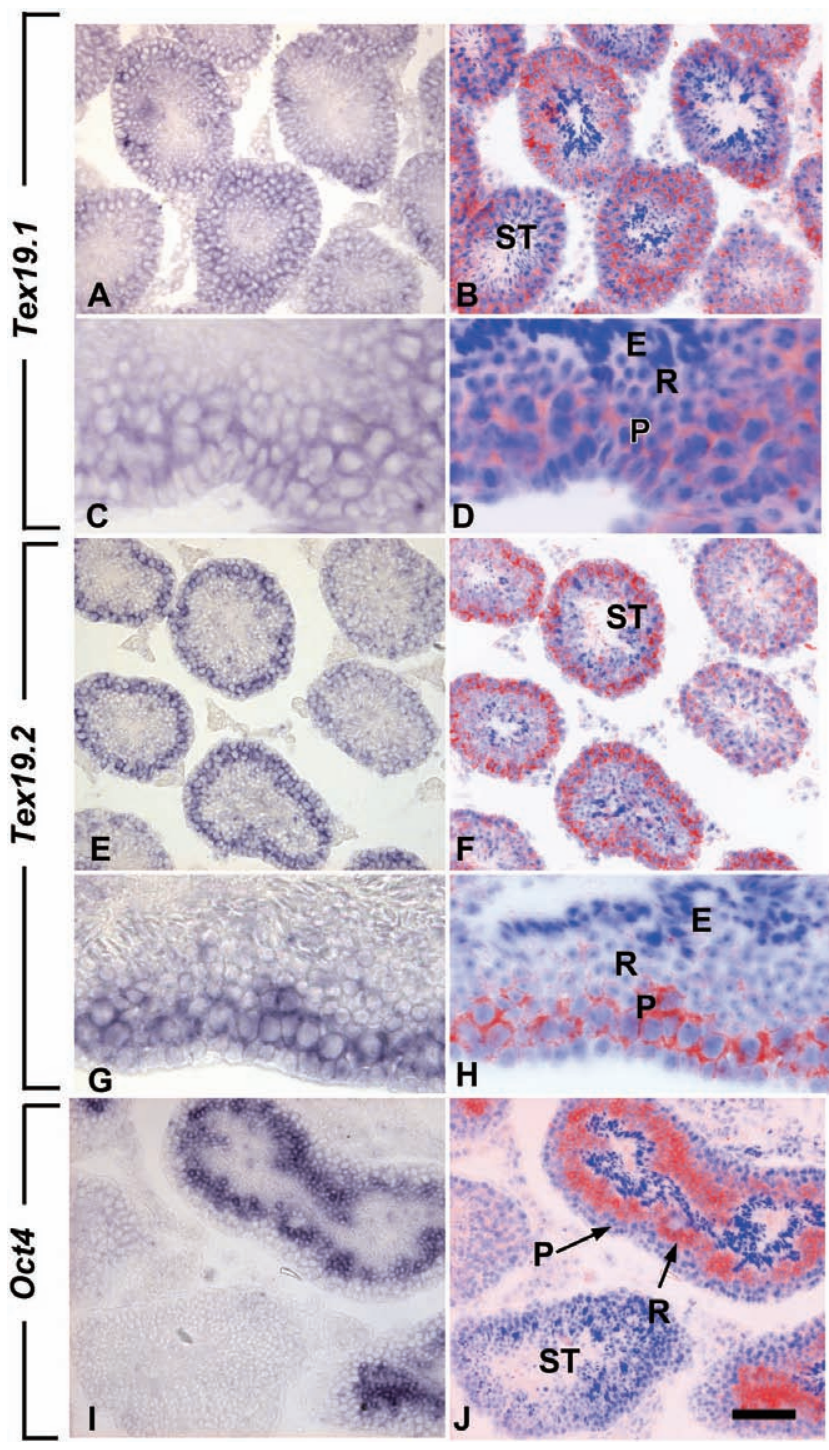

Fig. 6. ISH analysis of Tex19.1, Tex19.2 and Oct4 expression in the adult testis. E, elongated spermatids; P, pachytene spermatocytes; R, round spermatids; ST, seminiferous tubules. ISH signals are purple. The histological sections displayed in A, C, E, G and I were counterstained with 4'-,6-diamidino-2-phenylindole dihydrochloride (DAPI), and the ISH signals were converted into a red false color in the merged pictures $(\mathrm{B}, \mathrm{D}, \mathrm{F}, \mathrm{H}$ and $\mathrm{J}$, respectively). Bar in J: $80 \mu \mathrm{m}$ (A, B, E, F, I and J) and $30 \mu \mathrm{m}(\mathrm{C}$, $\mathrm{D}, \mathrm{G}$ and $\mathrm{H})$.

that Tex19 is duplicated in the mouse and rat, giving rise to Tex19.1 and Tex19.2 paralogs [2]. A preliminary study of their expression patterns [2] shows that Tex19.1 transcripts are present in the placenta but are otherwise germ cell specific in both the male and female. Tex19.1 knockout mice display a reduced male fertility and a perinatal lethality affecting about half of the mutants [4]. The placenta, whose potential defects could account for the lethal phenotype of the Tex19.1 mutants, was however not analyzed. Furthermore, the two Tex19.1 knockout studies [3, 4] do not address a possible functional

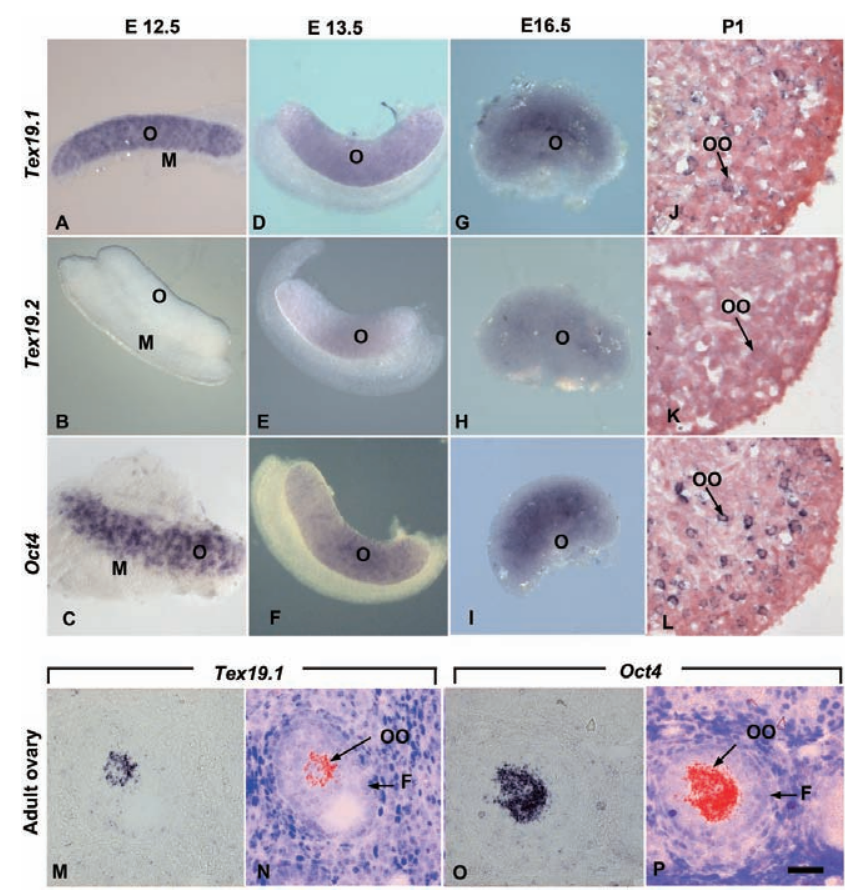

Fig. 7. ISH analysis of Tex19.1, Tex19.2 and Oct4 expression in the developing (A-L) and adult (M-P) ovary. F, ovarian follicle; $\mathrm{M}$, mesonephros; O, ovary; OO, oocyte. ISH signals are purple. The histological sections displayed in $\mathrm{J}-\mathrm{L}$ were counterstained with safranin. The histological sections displayed in $\mathrm{M}$ and $\mathrm{O}$ were counterstained with DAPI, and ISH signals were converted into a red false color on the merged pictures ( $\mathrm{N}$ and $\mathrm{P}$, respectively). Note that A-C, D-F and G-I were photographed at the same magnifications, respectively. Bar in P: $40 \mu \mathrm{m}(\mathrm{J}-\mathrm{L})$ and $30 \mu \mathrm{m}$ (M-P).

redundancy between Tex19.1 and Tex19.2. This redundancy can only operate providing that the two genes display overlapping expression domains or if the knockout of a given paralog induces an ectopic expression of the remaining one. Therefore, there was a need to fully address the expression pattern of Tex19.1 and to establish that of Tex19.2.

In the present study, expression of these genes was analyzed by RT-PCR and/or ISH from E6.5 to adulthood. Tex19.1 is present in blastocysts [2] and at E6.5. Tex19.2 is not expressed before E7.5. At E7.5, Tex19.1 and Tex19.2 show overlapping expression in the ectoderm, whereas only Tex19.1 is expressed in the ectoplacental cone. At E9.5, Tex19.1 and Tex19.2 expression is limited to cells which, according to their specific localization in the hindgut and their expression of Oct4, are known to represent migrating PGCs. When testes differentiate, Tex19.1 and Tex19.2 expression also overlap in the seminiferous cords of the fetal testis until E16.5. From E18.5 to soon after birth, a differential expression is observed between germ and somatic cells, as previously described [2]. Tex19.1 expression is then specific to germ cells, whereas Tex19.2 is mainly expressed in somatic cells. In adults, both genes are expressed in pachytene spermatocytes. The expression patterns of Tex19.1 and Tex19.2 reported in the present study are in accordance with the finding that (1) severely affected adult testes of Tex19.1 knockout mice lack all 
postmetiotic cells, their most advanced cell type being pachytene spermatocytes [4], and (2) spermatocytes lacking Tex19.1 display synapsis defects $[4,5]$. Moreover, the variability in the phenotype of Tex19.1 knockout males, favors the existence of a redundancy between Tex19.1 and Tex19.2 at some stages of development. The reason why both genes are temporarily expressed in different cell types remains an open question. In particular, the existence of common or divergent regulation factors for Tex19.1 and Tex19.2 expression remain to be investigated.

Tex19.1, but not Tex19.2, is also expressed in the early developing female gonad and oocytes as well as in the ectoplacental cone and placenta. The birth of a healthy individual not only involves an appropriate germ cell development but also the integrity of the placenta. Many genes have been ascribed a specific expression either in somatic or germ cells in the gonads and in placental cell populations. This is the case for Esxl [11] and a cluster of genes representing the Rhox homeobox gene family, which includes Rhox 5 (or Pem) [12], Rhox6 (or Psxl) [13] and Rhox9 (also known as Psx2 or Gpbox) [14]. Three of these genes have been successfully ablated in the mouse. The Esxl knockout results in embryonic growth retardation due to placental defects but in fertile adults [15]. The phenotype of Rhox knockout mice show either a subfertility [16] or no pathological phenotype [17]. The mild or absent placental pathologies in Rhox null mutants could be explained by a redundancy between these genes, as they share a high degree of homology and present overlapping expression patterns. The proximity of the two genes, Rhox 5 and Rhox 9 , has precluded the generation of mice carrying a Rhox $5 / R h o x 9$ double knockout and explains why this redundancy could not be challenged.

Similar to Esxl or members of the Rhox homeobox gene family, Tex19.1 presents expression limited to male and female gonads and the placenta. Our data indicate that in the male mouse, Tex19.1 and Tex19.2 expression domains mainly overlap during development and adulthood. In their knockout study of Tex19.1, Ollinger et al. [4] detected a slight upregulation of Tex19.2 expression in the mutant testes that could eventually explain the variability of the Tex19.1 knockout phenotype. Our present study supports this scenario, as both genes are expressed in PGCs, gonocytes and pachytene spermatocytes. Kuntz et al. [2] have shown that Tex19.2 is specifically expressed in somatic cells of the testis at E18.5, which we confirm here and also observe from birth to P5. Surprisingly, we detected this expression in germ cells in adult testes. The stage-dependent expression of Tex19.2 may reflect a specific need for Tex19 in somatic cells during testis development. Besides, the ectoplacental cone and placental Tex19.1 expression that we show here could also explain why pups were missing in knockout animals [4]. Therefore, only a double Tex19.1/Tex19.2 inactivation in the same mouse to impair functional redundancy between these paralogs could allow for determination of their exact functions.

Although the present study focuses solely on transcripts, it is noteworthy that we showed previously that Tex19.1 and Tex19.2 proteins were localized in the nucleus of NIH3T3 cells. In contrast, Ollinger et al. [4] and Yang et al. [3] reported a cytoplasmic localization of the Tex19.1 protein in ES cells [4] and in male germ cells undergoing meiosis [3, 4]. Differences in the cell types used in these experiments and/or in the epitopes recognized by antibodies generated in different laboratories may explain these discrepancies.

\section{Acknowledgments}

We thank the IGBMC common facilities for technical support. This work was supported by the Centre National de la Recherche Scientifique (CNRS), Institut National de la Santé et de la Recherche Médicale (INSERM) (Grant Avenir), the Association Française contre les Myopathies (AFM), the Fondation pour la Recherche Médicale (FRM) and the Ministère de l'Education Nationale, de l'Enseignement Supérieur et de la Recherche.

\section{References}

1. Wang PJ, McCarrey JR, Yang F, Page DC. An abundance of X-linked genes expressed in spermatogonia. Nat Genet 2001; 27: 422-426. [Medline] [CrossRef]

2. Kuntz S, Kieffer E, Bianchetti L, Lamoureux N, Fuhrmann G, Viville S. Tex19, a mammalian-specific protein with a restricted expression in pluripotent stem cells and germ line. Stem Cells 2008; 26: 734-744. [Medline] [CrossRef]

3. Yang F, Cheng Y, An JY, Kwon YT, Eckardt S, Leu NA, McLaughlin KJ, Wang PJ. The ubiquitin ligase Ubr2, a recognition E3 component of the $\mathrm{N}$-end rule pathway, stabilizes Tex19.1 during spermatogenesis. PLoS One 2010; 5: e14017. [Medline] [CrossRef]

4. Öllinger R, Childs AJ, Burgess HM, Speed RM, Lundegaard PR, Reynolds N, Gray NK, Cooke HJ, Adams IR. Deletion of the pluripotency-associated Tex19.1 gene causes activation of endogenous retroviruses and defective spermatogenesis in mice. PLoS Genet 2008; 4: e1000199. [Medline] [CrossRef]

5. Zeng M, Lu Y, Liao X, Li D, Sun H, Liang S, Zhang S, Ma Y, Yang Z. DAZL binds to 3'UTR of Tex19.1 mRNAs and regulates Tex19.1 expression. Mol Biol Rep 2009; 36: 2399-2403. [Medline] [CrossRef]

6. Henrique D, Adam J, Myat A, Chitnis A, Lewis J, Ish-Horowicz D. Expression of a Delta homologue in prospective neurons in the chick. Nature 1995; 375: 787-790. [Medline] [CrossRef]

7. Pesce M, Scholer HR. Oct-4: control of totipotency and germline determination. $M o l$ Reprod Dev 2000; 55: 452-457. [Medline] [CrossRef]

8. Babaie Y, Herwig R, Greber B, Brink TC, Wruck W, Groth D, Lehrach H, Burdon T, Adjaye J. Analysis of Oct4-dependent transcriptional networks regulating self-renewal and pluripotency in human embryonic stem cells. Stem Cells 2007; 25: 500-510. [Medline] [CrossRef]

9. Yoshimizu T, Sugiyama N, De Felice M, Yeom YI, Ohbo K, Masuko K, Obinata M, Abe K, Scholer HR, Matsui Y. Germline-specific expression of the Oct-4/green fluorescent protein (GFP) transgene in mice. Dev Growth Differ 1999; 41: 675-684. [Medline] [CrossRef]

10. Ohmura M, Yoshida S, Ide Y, Nagamatsu G, Suda T, Ohbo K. Spatial analysis of germ stem cell development in Oct-4/EGFP transgenic mice. Arch Histol Cytol 2004; 67: 285-296. [Medline] [CrossRef]

11. Wang X, Zhang J. Rapid evolution of primate ESX1, an X-linked placenta- and testis-expressed homeobox gene. Hum Mol Genet 2007; 16: 2053-2060. [Medline] [CrossRef]

12. Sutton KA, Wilkinson MF. The rapidly evolving Pem homeobox gene and Agtr2, Ant2, and Lamp2 are closely linked in the proximal region of the mouse $\mathrm{X}$ chromosome. Genomics 1997; 45: 447-450. [Medline] [CrossRef]

13. Daggag H, Svingen T, Western PS, van den Bergen JA, McClive PJ, Harley VR, Coopman P, Sinclair AH. The rhox homeobox gene family shows sexually dimorphic and dynamic expression during mouse embryonic gonad development. Biol Reprod 2008; 79: 468-474. [Medline] [CrossRef]

14. Takasaki N, McIsaac R, Dean J. Gpbox (Psx2), a homeobox gene preferentially expressed in female germ cells at the onset of sexual dimorphism in mice. Dev Biol 2000; 223: 181-193. [Medline] [CrossRef]

15. Li Y, Behringer RR. Esx 1 is an X-chromosome-imprinted regulator of placental development and fetal growth. Nat Genet 1998; 20: 309-311. [Medline] [CrossRef]

16. MacLean JA 2nd, Chen MA, Wayne CM, Bruce SR, Rao M, Meistrich ML, Macleod C, Wilkinson MF. Rhox: a new homeobox gene cluster. Cell 2005; 120: 369-382. [Medline] [CrossRef]

17. Takasaki N, Rankin T, Dean J. Normal gonadal development in mice lacking GPBOX, a homeobox protein expressed in germ cells at the onset of sexual dimorphism. Mol Cell Biol 2001; 21: 8197-8202. [Medline] [CrossRef] 